\title{
Clusters of health behaviors and their relation to body mass index among adolescents in Northern Finland
}

\begin{abstract}
Aims To identify clusters of health behaviors among Finnish adolescents and examine whether these clusters are associated with body mass index (BMI).

Methods The data, drawn from the prospective population-based Northern Finland Birth Cohort 1986, comprised a total of 7,182 adolescents who replied to a follow-up postal questionnaire at the age 15 to 16. The adolescents were asked about multiple health behaviors, such as physical activity, screen time, cigarette smoking, alcohol use and diet. Adolescents who answered the questions concerning all of these variables were included in the study, yielding a final sample of 4,305 subjects. K-means cluster analysis was performed to identify group of adolescents with similar health behaviors. Chisquare tests were performed to analyze the association between the clusters and BMI.

Results Two clusters - Healthy Lifestyle and Unhealthy Lifestyle - were identified for both genders. The values of all the studied variables differed significantly between the clusters identified for both boys and girls. No significant relationship between the identified clusters and BMI was found for either boys or girls.

Conclusions It is important to consider multiple lifestyle-related behaviors and trying to identify groups that present probability for developing lifestyle diseases.
\end{abstract}

Key words: adolescent, health behavior, BMI, cluster analysis, physical activity, screen time, diet, smoking, alcohol drinking

\section{Word Count: 192}




\section{Introduction}

Adolescence has been identified as a critical developmental period in between childhood and adulthood. A number of health behaviors begin already in adolescence and affect health both at the time and in later years. (1) The health behavior of adolescents needs improvement. A majority of adolescents do not meet physical activity recommendations $(2,3)$ and they spend a lot of time in front of various screens $(2,4)$. Although cigarette smoking among adolescents has significantly decreased during the past decades, 24 million adolescents aged 13-15 years smoke on the global level (5). Alcohol consumption among adolescents is another significant concern; more than a quarter of all 15-19-year-olds worldwide drink alcohol, with the prevalence reaching 50-70\% in many countries of the Americas, Europe and the Western Pacific (6). Previous research has also shown that adolescents' dietary behaviors should improve; they consume lots of fast food and sugary foods (8$10)$, while their intake of vegetables and fruits is insufficient $(7,8)$.

In Finland health behavior of adolescents is similar to global trends. More specifically, less than a quarter of 13-year-olds and only a fifth of 15-year-olds report at least one hour of moderate to vigorous physical activity per day (11). In addition, the same study points out that only $5 \%$ of children and adolescents aged 9 to 15 reported spending the maximum of two hours a day - or less - in front of screens. Smoking prevalence among adolescents has decreased significantly, yet slightly less than one-tenth of 16-year-old adolescents still use tobacco products daily. The declining trend in alcohol use among underaged adolescents observed during the past decades seems to have slowed down, while alcohol use among adolescents of legal age has been reported to be slightly increasing (12). There is also a concerning shortage of fruit, vegetable and berry intake among adolescents, and approximately one-tenth of adolescents eat sweets and/or drink sugar-sweetened beverages almost daily (13).

Health behavior choices have a major impact on adolescents' overall health and wellbeing. Adolescents with low levels of physical activity have lower self-related health, more health complaints (14) and a higher risk of obesity (15) than adolescents with higher levels of physical activity. Excessive screen time has been linked with higher BMI $(16,17)$, emotional problems and psychological distress (18), low life satisfaction and less physical activity (3). Risk behaviors such as smoking and alcohol use have been shown to cluster together and, as such, pose a real threat to adolescents' health and wellbeing (19). Smoking is associated with suicidal behavior, direct self- 
injurious behavior, anxiety, conduct problems and hyperactivity (20). Alcohol use in adolescence has been linked with depression (21), alcohol problems, and even premature death (22). Unhealthy eating habits and food choices are associated with adolescent overweight and obesity $(15,17)$.

Overweight and obesity among children and adolescents is a global health concern. There is clear evidence that the prevalence of overweight and obesity among children and adolescents has increased substantially in the last decades (23). This is a worrying finding, as overweight and obesity among children and adolescents is known to increase the likelihood of developing metabolic syndrome (24) and cardiovascular disease (25) later in adulthood. Overweight and obesity during adolescence have also been linked with higher morbidity and mortality rates later in life; therefore, the recent trend of overweight and obesity may attenuate the historical increase in life expectancy (26). Being overweight is not just a physical problem, but also negatively affects childrens' and adolescents' psychosocial health (27).

It is important to investigate childrens' and adolescents' overall health behavior practices instead of focusing on their individual health behaviors. Determining which health behaviors cluster together can lead to a more complete understanding of the health behaviors - along with overall wellbeing during childhood and adolescence $(28,29)$. Previous studies have identified various health behavior patterns among adolescents (30). Unhealthy behaviors have been found to cluster together, a phenomenon which increases health risks among adolescents. For example, the combination of poor eating behavior and excessive screen time is associated with unhealthy weight control behavior (29), while the combination of excessive media use, low physical activity and poor diet quality is associated with overweight (31). Moreover, the combination of low levels of physical activity and poor eating is associated with psychosocial risks (29). The adverse consequences of unhealthy choices may be mitigated by healthy behaviors that group together (32); for example, excessive media use may be compensated for by high levels of physical activity and average diet quality (31).

Researchers have suggested that multiple combinations of health behaviors should be considered to prevent obesity among children and adolescents (28,29). Addressing multiple health behaviors simultaneously may help in designing future interventions for the prevention of childhood and adolescent overweight (28). Findings show that obesogenic cluster patterns are mixed, and the associations between them and health behavior remain inconclusive (30). Therefore, these clustered health behaviors need to be better understood to provide more data to identify unhealthy health behaviors of particular groups of adolescents, who are at risk of developing unfavorable health 
outcomes. The primary aim of this study was to identify clusters of health behavior among 15 to 16year-old Finnish adolescents in a population-based sample. A secondary aim was to determine whether these clusters are associated with BMI. In this study, health behavior consists of physical activity, screen time, diet, cigarette smoking and alcohol use.

\section{Methods}

\section{Data}

The study population comprises individuals who were part of a longitudinal, population-based research program - Northern Finland Birth Cohort 1986 (NFBC1986) - which aims to promote health and well-being. NFBC1986 includes health care records, questionnaires and clinical examinations as well as data on parents and offspring born between July 1985- June 1986 in Northern Finland (provinces of Oulu and Lapland) (33). In 2001 a follow-up postal questionnaire was sent to all living members of the cohort $(n=9215)$. Total of 7,182 adolescents replied the survey. The questionnaire contained a wide range of questions, including some that concern health behaviors. The questionnaire was tested and validated before its initialization. Participation was voluntary and based on informed consent. The respondents were not identifiable at any point in the study. Only adolescents who answered the questions concerning all the variables surveyed in this study were included. The final sample included 4,305 subjects.

\section{Measures}

\section{Physical activity}

Physical activity was measured with the question: "How many hours do you practice vigorous exercise outside of school hours? (getting out of breath and sweating at least mildly)". Response categories ranged from " $1=$ not at all" to " $6=$ seven hours a week or more". The variable was categorized into three different categories: $1=$ not at all to about an hour per week; $2=2-3$ hours per week; and 3 =about 4 hours to 7 hours per week.

\section{Screen time}


Screen time was assessed with two questions: "On average, how many hours a day do you watch TV outside of school hours?" and "On average, how many hours a day do you play or use the computer and/or video games outside of school time?". A sum variable was created based on the reported hours. The sum variable was then categorized into two groups: less than or equal to two hours per day and more than two hours per day.

\section{Cigarette smoking}

Cigarette smoking was evaluated with the following question: "At the present time, do you smoke cigarettes?" The answer alternatives ranged from " $1=$ not at all" to " $6=7$ days per week". The variable was categorized into three different categories: $1=$ not at all; $2=$ occasionally to $2-4$ days a week; and $3=5$ to 7 days a week.

\section{Alcohol use}

Alcohol use was assessed with the following question: " Have you ever drank or do you still - even occasionally - drink some alcoholic beverages?" The answer alternatives ranged from "1=never" to "6=at least once a week or more". The variable was categorized as follows: $1=$ never to have tasted but do not presently consume; 2 = consume casually to consume about once a month; and $3=$ consume 2-3 times a month to consume at least once a week or more.

\section{Diet}

Intake of sugary foods was measured using the following five questions: "How often do you usually eat cakes and cookies?"; "How often do you usually eat ice cream?"; "How often do you usually consume sugary beverages?"; "How often do you usually eat chocolate?"; and "How often do you usually eat sweets?". Response categories for each question ranged from "1=less than once a month or not at all" to "7=once a day or more". A sum variable representing intake of sugary foods was created based on responses these five questions.

Fast food intake was measured using the following three questions: "How often do you usually eat french fries or fried potatoes?"; "How often do you usually eat hamburgers or pizza?"; and "How often do you usually eat chips?" Response categories for each question ranged from "1=less than 
once a month or not at all" to " $7=$ once a day or more". A sum variable representing fast food intake was created based on the responses to these questions.

Fruit, vegetable and berry intake was probed using the following three questions: "How often did you eat uncooked vegetables (excluding potatoes) - whole, grated or as a salad - during the past week?"; "How often did you eat uncooked fruit or fruit salad during the past week?"; and "How often did you eat berries (including desserts made of berries) during the past week?" Response categories for each question ranged from " $1=$ not at all" to " $4=6-7$ times per week", and a sum variable for fruit, vegetable and berry intake was created based on the responses.

\section{BMI}

BMI was calculated by dividing a participant's self-reported weight (in kilograms) by their height (in meters squared). For both genders weight status was then divided into four groups: underweight (boys $<16.5 \mathrm{~kg} / \mathrm{m}^{2}$, girls $<16.2 \mathrm{~kg} / \mathrm{m}^{2}$ ); normal weight (boys $=16.5-23.5 \mathrm{~kg} / \mathrm{m}^{2}$, girls=16.2-24.1 kg/m²); overweight (boys=23.5-27.9 kg/m², girls=24.1-28.9 kg/m²); and obese (boys $>27.9 \mathrm{~kg} / \mathrm{m}^{2}$, girls $>28.9$ $\mathrm{kg} / \mathrm{m}^{2}$ ) according to WHO's international definitions for children and adolescents (34).

\section{Data analysis}

All of the data analyses and tests were performed using SPSS for Windows (version 25.0; IBM, Armonk, NY, USA). Cluster analysis was used to identify clusters of adolescents with similar health behavior patterns. Cluster variables were first standardized with z-scores to minimize the influence of variables with larger absolute measurement ranges relative to those with smaller ranges. The cluster analysis performed in this study employed the k-means non-hierarchical method. The analyses were performed separately according to gender due to differences in selected variables.

Two-, three-, four-, and five-cluster solutions were tested to identify the most reliable cluster solution. The reliability and stability of these solutions were tested by randomly taking two subsamples (50\%) of the total sample and repeating the analyses on these subsamples. The kappa coefficient was calculated to check how clusters in the subsamples agreed with those in the original data. Based on these tests, a two-cluster solution turned out to be the most meaningful representation of the study population for both boys and girls. The kappa values for both boys (0.945 and 0.942) and girls (0.989 and 0.956 ) indicated excellent agreement between the subsamples and the original data set (35). Once 
the clusters were identified, chi-square tests were performed to analyze associations between the clusters and BMI, while ANOVA and a post-hoc Bonferroni test were used to investigate be-tweencluster differences in terms of the measured health behavior indices.

\section{Results}

Participant characteristics $(n=4,305)$ are listed in Table 1. Of the participants, $47 \%(2,003)$ were boys and 2,302 were girls. Overall, boys were more physically active but also spent more time in front of screens than girls. Girls were more frequently cigarette smokers and alcohol users than boys. Girls' diets were healthier when compared to those of boys, i.e. relative to boys, girls ate vegetables, fruits and berries more often and sugary foods and fast food less often. Overweight and obesity were more prevalent among boys than girls.

\section{Identified clusters}

A cluster analysis of health behaviors (physical activity, screen time, cigarette smoking, alcohol use and diet) revealed two reliable clusters. These two clusters were identified for both genders. The values of all the studied variables differed significantly between the clusters identified for both boys and girls. Figures 1 and 2 present the final cluster solutions for boys and girls, respectively. For both genders, the identified clusters were labelled Healthy Lifestyle and Unhealthy Lifestyle. The means of the identified clusters and row values (mean \pm standard deviation) are presented in Table 2 .

The Healthy Lifestyle cluster was found for both genders. A slightly higher proportion of boys (61\%; $\mathrm{n}=1215)$ than girls $(58 \% ; \mathrm{n}=1340)$ were grouped in this cluster. This cluster showed the most positive scores in terms of all health behaviors. For both genders, this cluster showed higher than average scores (above 0 ) on physical activity and fruit, vegetable and berry intake, while screen time, alcohol use, cigarette smoking, fast food intake and sugary food intake all showed negative z-scores.

The Unhealthy Lifestyle cluster was found for both genders. A slightly higher proportion of girls ( $42 \% ; n=962)$ than boys $(39 \% ; n=788)$ were grouped in this cluster. This cluster represents unhealthy health behaviors for all of the variables. The boys and girls in this group showed higher than average scores (above 0) for screen time, alcohol use, cigarette smoking, fast food intake and sugary foods intake. Furthermore, the members of this group had negative z-scores for both physical activity and 
fruit, vegetable and berry intake. For both genders, this cluster differed the most from the healthy cluster in terms of alcohol use and cigarette smoking.

The values of all the studied variables differed significantly $(\mathrm{p}<0.001)$ between the clusters, and this difference was observed for the clusters representing both boys and girls. For both genders, the main differences between the clusters were smoking and alcohol use. As such, smoking was the variable that differentiated the clusters the most, followed by alcohol use. Screen time and sugary foods intake were the variables that distinguished the clusters the least. Between-cluster differences in the variables are presented in table 2.

\section{Association between clusters and BMI}

No significant relationship between the identified clusters and BMI was identified for either the boys or girls ( $\mathrm{p}$-value $=0.091$ for boys, $\mathrm{p}$-value $=0.424$ for girls). Table 3 shows the distribution of the various BMI classes within clusters for both genders. A majority of the adolescents were in the normal weight class ( $81.5 \%$ of the boys and $87.6 \%$ of the girls). Overweight and obesity were more prevalent among boys ( $13.7 \%$ and $3.1 \%$, respectively) than girls ( $8.6 \%$ and $2.4 \%$, respectively). Only $1.7 \%$ of the boys and $1.4 \%$ of the girls belonged to the underweight category.

\section{Discussion}

Two reliable clusters were found for both genders. The cluster labelled as Healthy Lifestyle had the most positive scores for health behaviors. Members of this cluster showed higher than average scores concerning physical activity and fruit, vegetable and berry intake, as well as negative $\mathrm{z}$-scores for screen time, alcohol use, cigarette smoking, fast food intake and sugary food intake. A majority of the participating adolescents belonged to this cluster $-61 \%$ of boys and $58 \%$ of girls - which is in line with the findings of a previous Finnish cross-national study in which over half of the adolescents were classified as belonging in the healthy cluster (36).

The cluster labelled as Unhealthy Lifestyle was characterized by unhealthy behavior across all of the variables. Both boys and girls in this cluster had higher than average scores for screen time, alcohol use, cigarette smoking, fast food intake and sugary food intake, along with negative $\mathrm{z}$-scores for 
physical activity and fruit, vegetable and berry intake. For both genders, this cluster differed the most from the healthy cluster in terms of alcohol use and cigarette smoking.

Most studies that examine health behavior patterns among adolescents have not included alcohol use and cigarette smoking in their analyses (see, e.g., 41-45,). In the present study, alcohol use and smoking were the key variables that differentiated the clusters. This indicates that clustering analyses of adolescents' health behavior should include variables that describe alcohol use and smoking, as was previously suggested by Laxer et al. (37). The results of this study indicate that smoking and alcohol use cluster together, a phenomenon which has also been recognized in other studies $(19,38)$. This finding is concerning, as it suggests that adolescents who engage in these activities are also engaging in other risk behaviors as well (19). Furthermore, the present study found that alcohol use and smoking also cluster together with other unhealthy health behaviors; this finding is consistent with what has been reported in previous research $(37,39)$.

Although the identified clusters did not differ according to gender, we nevertheless found certain gender differences when the health behaviors were individually analyzed. For example, the finding that boys were more engaged in physical activity than girls, but also spent more time in front of screens, is consistent with previous research $(29,36,40)$. Furthermore, other studies have also recognized that among adolescents, girls have healthier diets than boys $(36,40)$. We found that girls consumed alcohol more often than boys, which is in line with another Finnish study (36). Girls also smoked cigarettes more frequently than boys, yet gender differences in this aspect of health have gradually decreased in the new millennium (12).

Comparisons of the number and structure of clusters between studies are challenging due to the fact that cluster analysis involves subjective decision-making that can affect the final number and types of clusters that are identified. Leech et al. (30) also suggest that cluster patterns may only be specific to the studied culture(s) and populations, and as such, results should always be generalized with caution. Previous research has yielded mixed results when attempting to cluster adolescents' health behaviors. Prior studies have reported both healthy and unhealthy patterns in health behaviors, as well as several complex patterns (i.e. including both healthy and unhealthy behaviors). (30.) In the present study, no clusters that included complex health behavior were identified. Instead, a healthy cluster defined by healthy levels for all the studied variables - and an unhealthy cluster - characterized by unhealthy values for all five indices - were identified. These findings are consistent with other studies which have shown distinct healthy $(29,36,40-42)$ and unhealthy $(31,42)$ clusters. 
In our study, the finding that physical activity and screen time cluster in healthy and unhealthy ways reflects what has been reported in previous studies $(36,42)$. Findings from other studies suggesting that high levels of physical activity and high levels of sedentary behavior cluster together $(31,40,43$, 44) indicate that the relationship between physical activity and screen time is more complex than what was shown in this study. The present study also revealed an unhealthy clustering of screen time and diet, which has also been found in previous studies $(29,45)$. These results are important when considering that the combination of low physical activity and excessive screen time have been found to associate with overweight and obesity (30), while excessive screen time combined with poor diet is associated with unhealthy weight control behavior (29).

The relationship between health behavior and obesity is very complex. Previous research has provided inconsistent support for an association between cluster patterns and overweight. Some studies have found no association between identified clusters and overweight $(30,37)$ while other studies have found a higher prevalence of overweight in unhealthy clusters $(29,30)$. Nuutinen et al. (36) examined how cluster patterns are associated with overweight among Finnish adolescents; the results indicate that there is a greater risk of overweight among girls in the unhealthy cluster even though overall overweight was more prevalent among boys. No significant BMI differences were found among the clusters identified in this study, but the finding that overweight and obesity were more prevalent among Finnish boys was consistent with what had been reported by Nuutinen et al. (36). The previous inconsistent findings regarding the association between health clusters and overweight could have resulted from the fact that overweight and obesity may be more prone to emerging over the long-term. Therefore, more research that investigates the longitudinal relationship between clusters identified during adolescence and BMI is needed. This type of research would be relevant as both overweight and obesity among children and adolescents has substantially increased on a global level over the past few decades (23). In this study, the participants self-reported their height and weight. Previous studies have shown that there is discrepancy between self-reported and measured heights and weights among adolescents (46, 47). Adolescents, especially girls, have a tendency to underestimate their weight, which may have caused bias in the prevalence of overweight and obesity (46). This could explain why no significant associations between BMI and the identified clusters were detected in this study.

The main strength of the present study is the large, representative sample $(n=4,305)$ of Finnish adolescents. A few limitations of this study should also be taken into account. NFBC1986 is based 
on self-reported information and, as such, could be considered as a problematic method for collecting data. The large sample size may have helped minimize this issue because individual misrepresentations exert less influence on the data set. In this study cigarette smoking, alcohol use, and diet were measured by days of use, not by amounts of use. This approach may be defective when trying to assess total consumption of these products. One limit of this study is the cross-sectional data, which does not support the investigation of causal relationships.

The results of this study may not be generalizable to the present as the analyzed data were collected in 2001. However, the results of this study provide a basis for future studies as NFBC1986 provides longitudinal data - spanning the antenatal period up to the present. In this way, this study provides many possibilities for future research. Future studies could add information regarding which childhood factors, e.g. parent's socio-economic status, associate with the clusters identified in this study. Next follow-up survey for NBFC1986 respondents will take place in 2019 so it would also be interesting to research how the identified clusters are associated with health behavior and lifestyle choices, such as problematic gaming behavior, later in the lives of the respondents.

This study provides information about how health behaviors cluster among adolescents. In this study, we identified two health behavior clusters which showed striking similarities for both genders. The results of this study, along with what has previously been reported, show how important it is to consider multiple lifestyle-related behaviors when classifying adolescents and trying to identify subgroups that are at risk for developing lifestyle diseases. Identifying these subgroups would be pivotal to the creation of prevention strategies that specifically target high-risk individuals. 


\section{References}

1. WHO. Health for the world's adolescents. A second chance in the second decade. Geneva, Switzerland: World Health Organization; 2018.

2. Kann L, McManus T, Harris W, Shanklin SL, Flint KH, Queen B, et al. Youth Risk Behavior Surveillance — United States, 2017. MMWR Surveill Summ 2018; 67(8):1-114.

3. Kessaram T, McKenzie J, Girin N, Merilles OEA Jr, Pullar J, Roth A, et al. Overweight, obesity, physical activity and sugar-sweetened beverage consumption in adolescents of Pacific islands: results from the Global School-Based Student Health Survey and the Youth Risk Behavior Surveillance System. BMC Obes 2015; 2(34):1-10.

4. Ngantcha M, Janssen E, Godeau E, Ehlinger V, Le-Nezet O, Beck F, et al. Revisiting factors associated with screen time media use: a structural stude among school-aged adolescents. $J$ Phys Act Health 2018; 15(6):448-56.

5. WHO. WHO Global Report on Trends in Prevalence of Tobacco Smoking 2000-2025, 2nd ed. Geneva, Switzerland: World Health Organization; 2018.

6. WHO. Global Status Report on Alcohol and Health 2018. Geneva, Switzerland: World Health Organization; 2018.

7. Moore LV, Thompson FE, Demissie Z. Percentage of youth meeting federal fruit and vegetable intake recommendations, youth risk behavior surveillance system, United States and 33 states, 2013. J Acad Nutr Diet 2018; 117(4):545-53.

8. Zalewska M, Maciorkowska E. Selected nutritional habits of teenagers associated with overweight and obesity. PeerJ 2017; 5:e3681.

9. Mesana MI, Hilbig A, Androutsos O, Cuenca-García M, Dallongeville J, Huybrechts I, et al. Dietary sources of sugars in adolescents' diet: the HELENA study. Eur J Nutr 2016; 57(2):629-41.

10. Braithwaite I, Stewart AW, Hancox RJ, Beasley R, Murphy R, Mitchell EA, et al. Fast-food consumption and body mass index in children and adolescents: an international crosssectional study. BMJ Open 2014; 4(12):1-9.

11. Kokko S, Mehtälä A, Villber J, Ng K, Hämylä R. Itsearvioitu liikunta-aktiivisuus, istuminen ja ruutuaika sekä liikkumisen seurantalaitteet ja -sovellukset (Self-evaluated physical activity, sitting, screen time, and monitoring devices and applications for exercising). In Lasten ja Nuorten Liikuntakäyttäytyminen Suomessa. LIITU-tutkimuksen tuloksia 2016 (Kokko S, Mehtälä A eds.). Helsinki, Finland: Valtion liikuntaneuvosto; 2016, 10-15.

12. Kinnunen JM, Pere L, Raisamo S, Katainen A, Ollila H, Rimpelä A. Nuorten Terveystapatutkimus 2017: Nuorten Tupakkatuotteiden Käyttö sekä Rahapelaaminen (Health habit survey of adolescents 2017: Adolescents' usage of smoking products and gambling). Helsinki, Finland: Ministry of Social Affairs and Health; 2017.

13. Terveyden ja hyvinvoinnin laitos. Kouluterveyskysely (School Survey) [Internet]. Helsinki, Finland: National Institute for Health and Welfare; 2017 [cited 2018 Oct 17]. Available from: https://sampo.thl.fi/pivot/prod/fi/ktk/ktk4/summary_perustulokset?alue_0=87869\&mittarit_ $0=200537 \&$ mittarit_1=\&mittarit_2=200285\#.

14. Galán I, Boix R, Medrano MJ, Ramos P, Rivera F, Pastor-Barriuso R, et al. Physical activity and self-reported health status among adolescents: a cross-sectional population-based study. BMJ Open 2013; 3(5):1-10.

15. Rathnayake KM, Roopasingam T, Wickramasighe VP. Nutritional and behavioral determinants of adolescent obesity: a case-control study in Sri Lanka. BMC Public Health 2014; 14(1291):1-6.

16. Falbe J, Rosner B, Willett WC, Sonneville KR, Hu FB, Field AE. Adiposity and different types of screen time. Pediatrics 2013; 132(6):1497-505. 
17. Kar S, Khandelwal B. Fast foods and physical inactivity are risk factors for obesity and hypertension among adolescent school children in east district of Sikkim, India. J Nat Sci Biol Med 2015; 6(2):356-9.

18. Rikkers W, Lawrence D, Hafekost J, Zubrick SR. Internet use and electronic gaming by children and adolescents with emotional and behavioural problems in Australia - results from the second Child and Adolescent Survey of Mental Health and Wellbeing. BMC Public Health 2016; 16(399):1-16.

19. Noel H, Denny S, Farrant B, Rossen F, Teevale T, Clark T, et al. Clustering of adolescent health concerns: a latent class analysis of school students in New Zealand. J Paediatr Child Health 2013; 49(11):935-41.

20. Banzer R, Haring C, Buchheim A. Factors associated with different smoking status in European adolescents: results of the SEYLE study. Eur Child Adolesc Psychiatry 2017; 26(11):1319-29.

21. Edwards AC, Heron J, Dick DM, Hickman M, Lewis G, Macleod J, et al. Adolescent alcohol use is positively associated with later depression in a population-based U.K. cohort. $J$ Stud Alcohol Drugs 2014; 75(5):758-65.

22. Marshall EJ. Adolescent alcohol use: risks and consequences. Alcohol Alcohol 2014; 49(2):160-4.

23. NCD Risk Factor Collaboration. Worldwide trends in body-mass index, underweight, overweight, and obesity from 1975 to 2016: a pooled analysis of 2416 population-based measurement studies in 128.9 million children, adolescents, and adults. Lancet 2017; 390(10113):2627-42.

24. Morrison JA, Aronson Friedman L, Gray-McGuire C. Metabolic syndrome in childhood predicts adult cardiovascular disease 25 years later: the Princeton Lipid Research Clinics Follow-up Study. Pediatrics 2007; 120(2):340-5.

25. Umer A, Kelley GA, Cottrell LE, Giacobbi P Jr, Innes KE, Lilly CL. Childhood obesity and adult cardiovascular disease risk factors: a systematic review with meta-analysis. BMC Public Health 2017; 17(683):1-24.

26. Twig G, Afek A, Shamiss A, Derazne E, Rabbi ML, Tzur D, et al. Adolescence BMI and trends in adulthood mortality: a study of 2.16 million adolescents. J Clin Endocrinol Metab 2014; 99(6):2095-103.

27. Riazi A, Shakoor S, Dundas I, Eiser C, McKenzie SA. Health-related quality of life in a clinical sample of obese children and adolescent. Health Qual Life Outcomes 2010; 8(134):16.

28. Gubbels JS, van Assema P, Kremers SPJ. Physical activity, sedentary behavior, and dietary patterns among children. Curr Nutr Rep 2013; 2(2):105-12.

29. Veloso SM, Matos MG, Carvalho M, Diniz JA. Psychosocial factors of different health behaviour patterns in adolescents: association with overweight and weight control behaviours. J Obes 2012; 2012:1-10.

30. Leech RM, McNaughton SA, Timperio A. The clustering of diet, physical activity and sedentary behavior in children and adolescents: a review. Int J Behav Nutr Phys Act 2014; 11(4):1-9.

31. Spengler S, Mess F, Schmocker E, Woll A. Longitudinal associations of health-related behavior patterns in adolescence with change of weight status and self-rated health over a period of 6 years: results of the MoMo longitudinal study. BMC Pediatr 2014; 14(1):1-11.

32. Cuenca-García M, Huybrechts I, Ruiz JR, Ortega FB, Ottevaere C, González-Gross M, et al. Clustering of multiple lifestyle behaviors and health-related fitness in European adolescents. J Nutr Educ Behav 2013; 45(6):549-57.

33. University of Oulu. Northern Finland Cohorts [Internet]. Oulu, Finland: University of Oulu; 2018 [cited 2018 Dec 17]. Available from: https://www.oulu.fi/nfbc/. 
34. WHO. Growth Reference 5-19 Years [Internet]. Geneva, Switzerland: World Health Organization; 2007 [cited 2018 Nov 15]. Available from: https://www.who.int/growthref/who2007 bmi for age/en/.

35. Cicchetti D, Bronen R, Spencer S, Haut S, Berg A, Oliver P, Tyrer P. Rating scales, scales of measurement, issues of reliability: resolving some critical issues for clinicians and researchers. J Nerv Ment Dis 2006; 194:557-564.

36. Nuutinen T, Lehto L, Ray C, Roos E, Villberg J, Tynjälä J. Clustering of energy balancerelated behaviours, sleep, and overweight among Finnish adolescents. Int $J$ Public Health 2017; 62:929-38.

37. Laxer RE, Brownson RC, Dubin JA, Cooke M, Chaurasia A, Leatherdale ST. Clustering of risk-related modifiable behaviours and their association with overweight and obesity among a large sample of youth in the COMPASS study. BMC Public Health 2017; 17(102):1-11.

38. Busch V, Van Stel HF, Schrijvers AJP, de Leeuw JRJ. Clustering of health-related behaviors, health outcomes and demographics in Dutch adolescents: a cross-sectional study. BMC Public Health 2013; 13(1118):1-11.

39. Regan Á, Heary C. Patterns of sedentary behaviours in Irish female adolescents. J Adolesc 2013; 36:269-78.

40. Ottervaere C, Huybrechts I, Benser J, De Bourdeaudhuij I, Cuenca-Garcia M, Dallongeville $\mathrm{J}$, et al. Clustering patterns of physical activity, sedentary and dietary behavior among European adolescents: The HELENA study. BMC Public Health 2011; 11(328):1-10.

41. Berlin KS, Kamody RC, Thurston IB, Banks GG, Rybak TM, Ferry RJ. Physical activity, sedentary behaviors, and nutritional risk profiles and relations to body mass index, obesity, and overweight in eighth grade. Behav Med 2017; 43(1):31-9.

42. Iannotti RJ, Wang J. Patterns of physical activity, sedentary behavior, and diet in U.S. adolescents. J Adolesc Health 2013; 53(2):280-6.

43. Maia GE, Moures Mendes L, Marçal Pimenta A, Bertazzi Levy R, Moreira Claro R. Cluster of risk and protective factors for obesity among Brazilian adolescents. Int J Public Health 2017; 63(4):481-90.

44. Moreira N, da Veiga GV, Santaliestra-Pasías AM, Androutsos O, Cuenca-García M, de Oliveira ASD, et al. Clustering of multiple energy balance related behaviors is associated with body fat composition indicators in adolescents: results from the HELENA and ELANA studies. Appetite 2018; 120:505-13.

45. Leech RM, McNaughton, Timperio A. Clustering of children's obesity-related behaviours: associations with sociodemographic indicators. Eur J Clinl Nutr 2014; 6(5)8:623-8.

46. Brettschneider A-K, Schaffrath Rosario A, Ellert U. Validity and predictors of BMI derived from self-reported height and weight among 11- to 17-year-old German adolescents from the KiGGS study. BMC Res Notes 2011; 4(414):1-11.

47. Fonseca H, Silva AM, de Matos MG, Esteves I, Costa P, Guerra A, Gomes-Pedro J. Validity of BMI based on self-reported weight and height and predictors of bias in adolescents. Acta Paediatr 2011; 99:83-8. 


\section{Tables}

Table 1 Descriptive statistics of health behaviors and BMI among 15- to 16-year-olds from the Northern Finland Birth Cohort 1986 follow-up survey in $2001(n=4305)$

\begin{tabular}{|c|c|c|}
\hline & $\begin{array}{l}\text { Boys } \\
(n=2003)\end{array}$ & $\begin{array}{l}\text { Girls } \\
(n=2302)\end{array}$ \\
\hline \multicolumn{3}{|l|}{ Physical activity (hours/week), \% } \\
\hline 0-1 hours/week & $30.3 \%$ & $42.6 \%$ \\
\hline 2-3 hours/week & $22.8 \%$ & $30.1 \%$ \\
\hline 4-7 hours/week & $46.9 \%$. & $27.3 \%$ \\
\hline Average screen time (hours: minutes/day) & $4: 27$ & $3: 11$ \\
\hline \multicolumn{3}{|l|}{ Cigarette smoking (days/week), \% } \\
\hline Don't smoke & $55.1 \%$ & $44.5 \%$ \\
\hline Occasionally up to 4 days/week & $23.2 \%$ & $29.7 \%$ \\
\hline 5-7 days/week & $21.4 \%$ & $25.8 \%$ \\
\hline \multicolumn{3}{|l|}{ Alcohol use, $\%$} \\
\hline Don't use at present & $43.6 \%$ & $31.3 \%$ \\
\hline Casually to about once a month & $41.8 \%$ & $49.5 \%$ \\
\hline More than 2 times a month & $14.6 \%$ & $19.2 \%$ \\
\hline Intake of sugary foods [5 (less than once a month)- 35 (daily)] & 17.3 & 16.7 \\
\hline Fast food intake [3 (less than once a month)- 21 (daily)] & 7.8 & 7.0 \\
\hline Fruit, vegetable and berry intake [3 (never)- 12 (daily/almost daily)] & 6.3 & 6.9 \\
\hline \multicolumn{3}{|l|}{ BMI (Body Mass Index), \% } \\
\hline Underweight & $1.7 \%$ & $1.4 \%$ \\
\hline Normal weight & $81.5 \%$ & $87.6 \%$ \\
\hline Overweight & $13.7 \%$ & $8.6 \%$ \\
\hline Obese & $3.1 \%$ & $2.4 \%$ \\
\hline
\end{tabular}

BMI: underweight (boys $<16.5 \mathrm{~kg} / \mathrm{m}^{2}$, girls $<16.2 \mathrm{~kg} / \mathrm{m}^{2}$ ); normal weight (boys=16.5-23.5 kg/m², girls=16.2-24.1 kg/m²); overweight (boys=23.5-27.9 kg/m², girls $=24.1-28.9 \mathrm{~kg} / \mathrm{m}^{2}$ ); and obese (boys $>27.9 \mathrm{~kg} / \mathrm{m}^{2}$, girls $>28.9 \mathrm{~kg} / \mathrm{m}^{2}$ ) 
Table 2 Mean values and percentages of health behavior indices by clusters among 15- to 16-year-olds from the Northern Finland Birth Cohort 1986 follow-up survey in $2001(n=4305)$

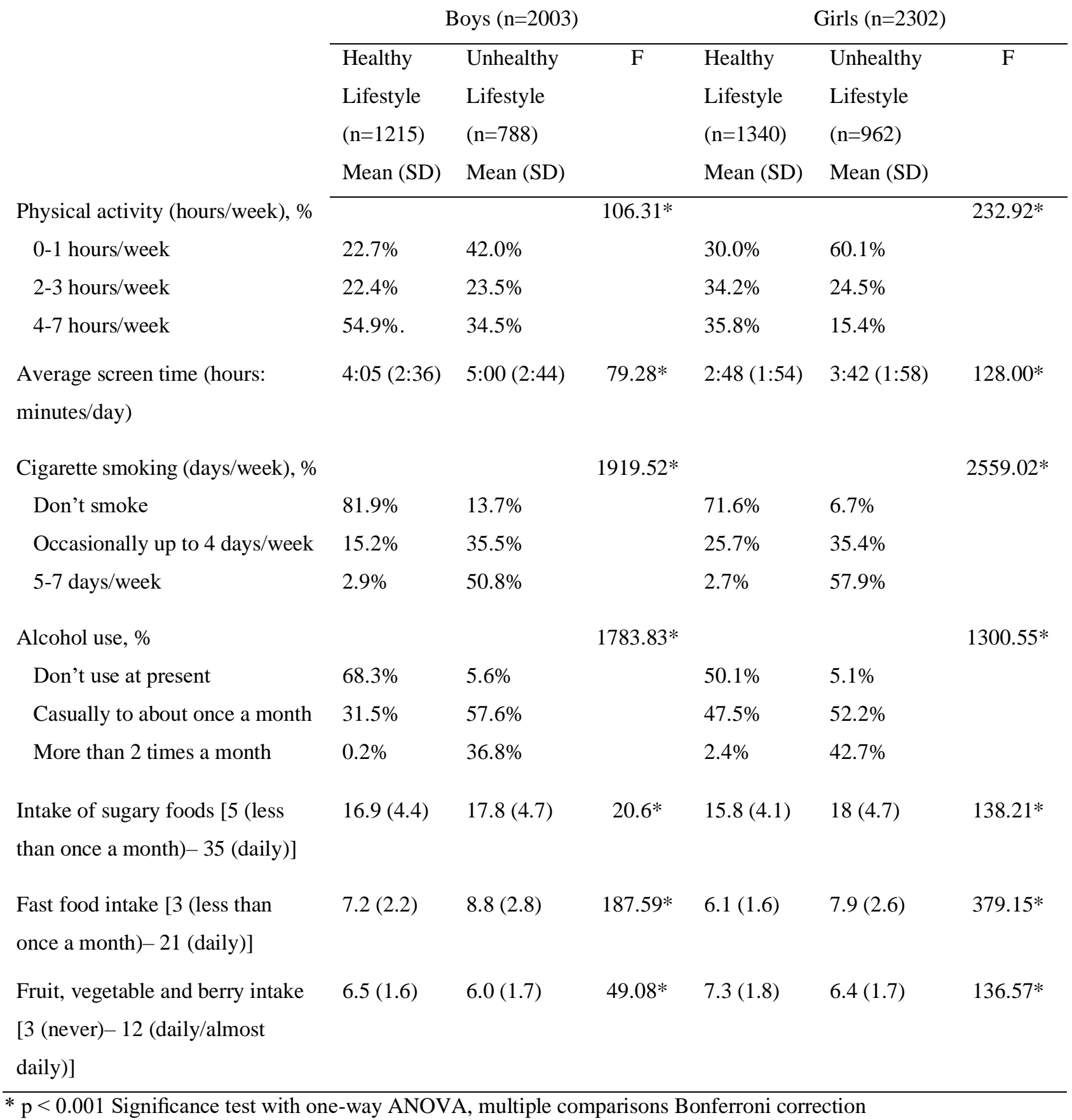


Table 3 Prevalence of BMI within clusters for both genders among 15- to 16-year-olds from the Northern Finland Birth Cohort 1986 follow-up survey in $2001(\mathrm{n}=4305)$

\begin{tabular}{|c|c|c|c|c|c|c|c|c|}
\hline & \multicolumn{4}{|c|}{ Boys $(n=2003)$} & \multicolumn{4}{|c|}{ Girls $(n=2302)$} \\
\hline & \multicolumn{2}{|c|}{$\begin{array}{l}\text { Healthy Lifestyle } \\
\qquad(n=2201)\end{array}$} & \multicolumn{2}{|c|}{$\begin{array}{l}\text { Unhealthy Lifestyle } \\
\qquad(\mathrm{n}=614)\end{array}$} & \multicolumn{2}{|c|}{$\begin{array}{l}\text { Healthy Lifestyle } \\
\qquad(\mathrm{n}=2577)\end{array}$} & \multicolumn{2}{|c|}{$\begin{array}{l}\text { Unhealthy Lifestyle } \\
\qquad(\mathrm{n}=780)\end{array}$} \\
\hline & $\mathrm{n}$ & $\%$ & $\mathrm{n}$ & $\%$ & $\mathrm{n}$ & $\%$ & $\mathrm{n}$ & $\%$ \\
\hline Underweight & 24 & 2.0 & 9 & 1.2 & 20 & 1.5 & 11 & 1.2 \\
\hline Normal weight & 970 & 82.6 & 609 & 79.7 & 1127 & 86.7 & 821 & 88.9 \\
\hline Overweight & 146 & 12.4 & 119 & 15.6 & 122 & 9.4 & 70 & 7.6 \\
\hline Obese & 34 & 2.9 & 27 & 3.5 & 31 & 2.4 & 22 & 2.4 \\
\hline
\end{tabular}

p-value (boys 0.091, girls 0.424) Significance test with Pearson chi-square

BMI: underweight (boys $<16.5 \mathrm{~kg} / \mathrm{m}^{2}$, girls $<16.2 \mathrm{~kg} / \mathrm{m}^{2}$ ); normal weight (boys=16.5-23.5 kg/m², girls=16.2-24.1 kg/m²);

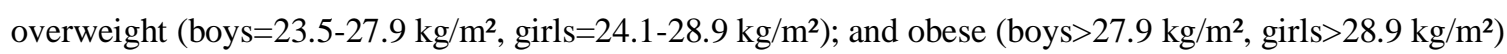




\section{Figure legends}

Fig. 1 Mean z-scores for the health behavior indices included in the two health clusters identified for 15- to 16-year-old boys $(\mathrm{n}=2003)$ in the Northern Finland Birth Cohort 1986 (Finland 2001)

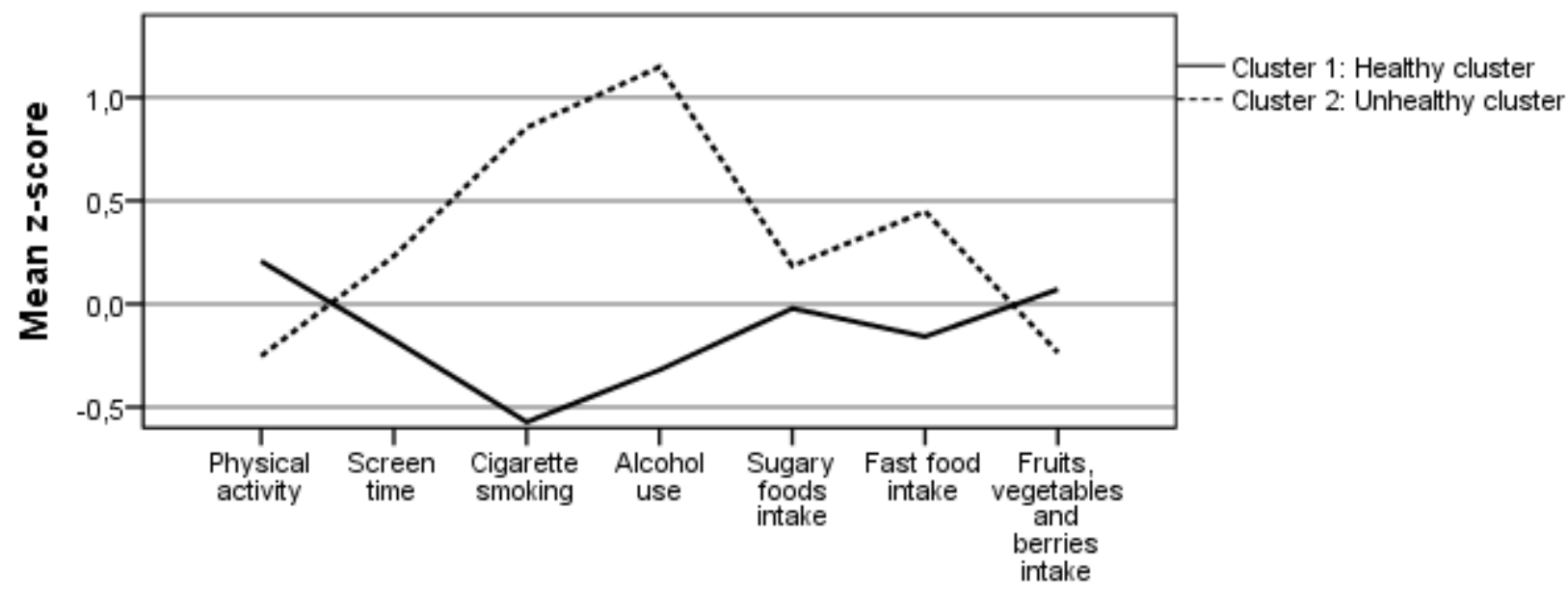

Fig. 2 Mean z-scores for the health behavior indices included in the two health clusters identified for 15- to 16-year-old girls $(n=2302)$ in the Northern Finland Birth Cohort 1986 (Finland 2001)

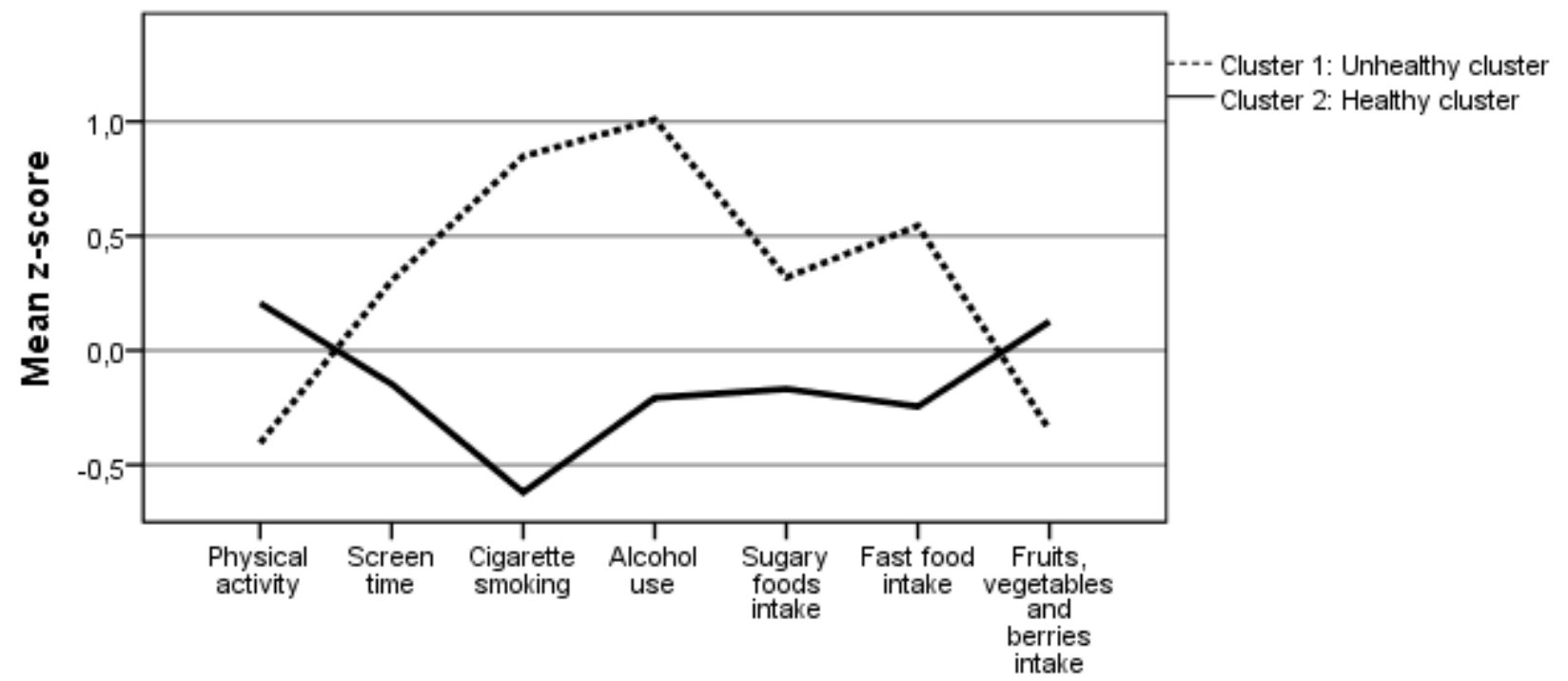

